Dr. Leonhard Stejneger exhibited a stuffed specimen of a willow grouse from Newfoundland, which he regarded as a new geographical race, differing from the continental form chiefly in the possession of more or less black upon its primaries. Mr. Brewster said that he had recently examined 150 specimens of ptarmigan from Newfoundland, and had observed the peculiarities pointed out, but did not consider them constant. IIe was inclined to regard the characters mentioned as seasonal, and possibly to some extent individual. Dr. Stejneger replied that this coloration of the wing feathers could not possibly be seasonal as they (the primaries) were moulted but once a year. Dr. Merriam stated that during a recent visit to Newfoundland he had examined a very large number of willow grouse in the flesh, and was still engaged in investigating the change of colour in this species. His studies led him to disagree with Dr. Stejneger's last statement. He (Dr. Merriam) was convinced that change in colour in individual feathers did take place, both independent of and coincident with the moult. Mr. D. G. Elliot agreed with Mr. Merriam in considering the change of colour of individual feathers an established fact. An animated discussion followed, and was participated in by Messrs. Irewster, Comeau, Coues, Elliot, Merriam, Ridgway, and Stejneger.

In response to a call from the President, Dr. P. L. Sclater said :- -

" I hope the members of the American Ornithologists' Union will excuse me if I offend the feelings of any one by the remarks I am about to make. It has aggrieved me much to find in this country three large and valuable collections of birds which are not under the care of paid working ornithologists. One of these is in Boston, one in New York, and the other in Philadelphia. Each contains what all ornithologists admit to be most valuable typical specimens. A grave responsibility rests upon the possessors of types of species, and the loss or injury of such specimens is a great and irreparable loss to science. The collection of the Boston Society of Natural History (known as the La Frenaye Collection) has been much damaged by neglect, and the entire collection ought to be catalogued and so arranged as to render any particular specimen readily accessible. In this building (the American Museum of Natural History in New York) are the types of the celebrated Maximilian Collection, and many other specimens of exceeding great value. A large number of these have never been properly identified, and some of them are missing and have doubtless been destroyed by insect pests. The value of others has been lost through neglect, by the displacement of labels, and by the omission of proper mcasures for their preservation. The same remarks would, in a gencral way, apply to the collections of the Philadelphia Academy of Natura Sciences. It is sad to find no paid ornithologists in charge of these exceedingly valuable collections, and I beg to suggest that the American Ornithologists' Union can undertake no worthier task than to impress upon the proper authorities the urgent necessity of immediate action in this matter."

The officers of the Union were re-elected as follows :-President, J. A. Allen, Cambridge; Vice-Presidents, Dr. Elliott Coues and Robert Ridgway, Washington; Secretary and Trcasurer, Dr. C. Hart Merriam, Locust Grove, New York.

The place of meeting for next year was referred to the Council for decision.

\section{TIE CAPILLARY CONSTANTS OF LIQUIDS AT THEIR BOILING-POINTS}

THE paper of Prof. Robert Schiff, published in Liebig's Annalen, March 1884 , on this subject, marks the first successful attempt out of many that have been made to connect the surface-tension of a liquid with its molecular constitution.

It has long been known that the tension diminishes rapidly with a risc of temperature, but the importance of this fact when it is desired to make a comparative examination of different liquids has not been fully appreciated or sufficiently insisted on till now by Prof. Schiff, who has to lament that, out of the considerable array of experimental investigations on the subject which he has examined, very few results could be extracted which could be usefully employed in such a comparative study, a failure which he attributes to the completely arbitrary and dissimilar physical conditions under which the different substances in question have been examined.

Since it is impossible to compare surface-tensions at the critical point, because that is the point at which the surface-tension vanishes, it is necessary to seek some other condition in which different liquids may be physically comparable, and that which naturally suggested itself for trial to Prof. Schiff, was the boilingpoint of the liquid itself, whose significance in this respect he has himself established.

The principle of his method was to select with great care two capillary glass tubes of perfectly cylindrical bore, but of different diameters, that of the wider being about $x^{\circ} 3 \mathrm{~mm}$., and of the narrower about half as much. These two tubes are then united into a little U-tube (about $7 \mathrm{~cm}$. long), which, after being partly filled with the experimental liquid, is hung in a wider vessel, at the bottom of which a little of the same liquid is kept boiling. From the difference of level of the liquid in these two connected capillary tubes, as measured at a temperature which must bc very nearly the boiling-point, the surface-tension at that temperature is readily deduced, since the method of procedure involves the thorough wetting of the upper portion of the tube with condensed liquid.

In this manner Prof. Schiff has determined the surface-tension at the boiling-point of some sixty liquids, with a possible error which he estimates at $\mathrm{r} \cdot 75$ per cent. of the mean value - at the worst, 2.4 per cent. His results may be stated as follows :-

I. For isomeric liquids that are chemically comparable, the surface-tension at the boiling-point is the same (within the limits of observational error). The observations do indeed point in the case of isomers of one class to a fall in surface-tension with a fall in the boiling-point, while in another class there is a perceptible risc with a rise in the boiling-point, but these variations are within the limits of possible errors of observation.

2. The quantity which turns out to be that on which attention should be fixed is not the surface-tension itself, but the surfacetension divided by the molecular weight, a quantity to which the author gives a vivid significance by pointing out that, in the case of a capillary elevation against a vertical wall wetted by the liquid, it is proportional to and represents the number of molecules raised above the free surface per unit length of the wall; for, since the tension per unit length is equal to the weight of the total number of molecules lifted, this tension divided by the weight of each molecule gives the total number lifted.

To the surface-tension in milligrams per millimetre divided by the relative molecular weight (and multiplied for convenience by 1000), Prof. Schiff accordingly assigns the symbol N, and his results show that not only is this number $\mathrm{N}$ the same for isomeric substances (as is implied in the previous statement), but that it is often the same for liquids of very different chemical constitution. He then proceeds to cxaminc the formula of such chemically different liquids which have the common property that $\mathrm{N}$ is the same, in the manner exemplified in the following illustration :"Taking all the different substances for which $\mathrm{N}$ is nearly 16 , we find-

$$
\begin{aligned}
& \text { Hexane, } \mathrm{C}_{6} \mathrm{H}_{14} \quad \ldots \quad \ldots \quad \ldots \mathrm{N}=\mathbf{I 6} \cdot \mathrm{I} \\
& \text { Xylol, ethyl-benzol, } \mathrm{C}_{8} \mathrm{H}_{10} \ldots \mathrm{N}=\left\{\begin{array}{l}
16^{\circ} \mathrm{O} \\
15^{\circ} \cdot 9 \\
15.8 \\
16.2
\end{array}\right. \\
& \text { With the formula } \mathrm{C}_{5} \mathrm{II}_{30} \mathrm{O}_{2} \ldots \mathrm{N}=\left\{\begin{array}{l}
16.2 \\
15.8 \\
15.6 \\
15.6 \\
15.9 \\
15.7
\end{array}\right.
\end{aligned}
$$

"This indicates that substances with the formulæ

$$
\mathrm{C}_{6} \mathrm{H}_{14}, \quad \mathrm{C}_{8} \mathrm{II}_{10}, \quad \mathrm{C}_{5} \mathrm{H}_{10} \mathrm{O}_{2},
$$

are, so far as concerns the value of the number (N) of mole. cules lifted, equivalent to each other.

" $\mathrm{C}_{6} \mathrm{H}_{14}$ differs from $\mathrm{C}_{8} \mathrm{H}_{10}$ in having $\mathrm{C}_{2}$ less and $\mathrm{H}_{4}$ more; accordingly, so far as concerns the constant $\mathrm{N}$,

$$
{ }_{2} \mathrm{C}={ }_{4} \mathrm{H} \text {. }
$$

" $\mathrm{C}_{8} \mathrm{H}_{10}$ differs from $\mathrm{C}_{5} \mathrm{H}_{10} \mathrm{O}_{2}$ in having $\mathrm{C}_{3}$ more and $\mathrm{O}_{2}$ less, so that, with reference to the constant $\mathrm{N}$,

$$
3 \mathrm{C}=2 \mathrm{O} \text {." }
$$

In order to test whether these equivalences are accidental or not, he examines other series, for which $\mathrm{N}$ has respectively the value $10.5,13,27, \& \mathrm{c}$., but always with the same result, so that he concludes that these equivalences are not chance coincidences, but that it is really possible to replace a certain number of atoms of one kind by a certain number of another kind without producing in the value of $\mathrm{N}$ an alteration which comes within the limits of frecise observation. 
From the equivalences $2 \mathrm{C}=4 \mathrm{H}$ and $3 \mathrm{C}=2 \mathrm{O}$ $\begin{array}{ll}\text { it follows that } & \mathrm{C}=2 \mathrm{H} \\ \text { and } & \mathrm{O}=3 \mathrm{H},\end{array}$ while from a similar examination of liquids containing chlorine he deduces $\mathrm{Cl}=7 \mathrm{H}$.

These equivalences enable him to write down what may be called the hydrogen equivalent, with respect to the value of the number $\mathrm{N}$, of any compound of the four elements in question, i.e. the number of hydrogen atoms, which, if they existed as a molecule in the free state, would constitute a substance for which the value of $\mathrm{N}$ at the boiling-point would be the same as for the original substance. Thus, selecting a few substances whose hydrogen equivalents are tolerably evenly distributed over the range that he has examined, he obtains the following table :-

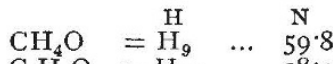

$$
\begin{aligned}
& \mathrm{C}_{2} \mathrm{H}_{6} \mathrm{O}=\mathrm{H}_{13} \quad \cdots \quad 3_{38} \cdot 4 \\
& \mathrm{C}_{3} \mathrm{H}_{8} \mathrm{O}=\mathrm{H}_{17} \quad \ldots \quad 29^{\circ} \mathrm{O} \\
& \mathrm{C}_{3} \mathrm{H}_{6} \mathrm{O}_{2}=\mathrm{H}_{18} \quad \ldots \quad 27^{\circ} \\
& \mathrm{C}_{4} \mathrm{H}_{8} \mathrm{O}_{2}=\mathrm{H}_{22} \quad \ldots 2^{\circ}{ }_{4} \\
& \mathrm{C}_{8} \mathrm{H}_{10}=\mathrm{H}_{26} \quad \ldots \quad \mathbf{I} 6 . \mathrm{I} \\
& \mathrm{C}_{9} \mathrm{H}_{12}=\mathrm{H}_{30} \quad \ldots \quad \mathbf{I}_{3} \cdot \mathbf{I} \\
& \mathrm{C}_{8} \mathrm{H}_{18}=\mathrm{H}_{34} \quad \ldots \quad 10.5
\end{aligned}
$$

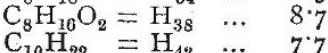

From these observations as data, a curve is easily drawn of which the ordinates are proportional to the number of atoms in the hydrogen equivalent and the abscissæ to the corresponding value of $\mathrm{N}$; and it is remarkable that the curve so drawn is of equable curvature, and corresponds equally well, not only to the selected data from which it is plotted, but also to all the other observed values of $\mathrm{N}$, so that by transforming the molecular formula of any liquid into its hydrogen equivalent we can at once find, by reference to the curve, the value of $\mathrm{N}$ for the substance, and, by multiplying this by $\frac{\text { mol. weigh }}{\text { IOOO }}$, we obtain the surface-tension at the boiling-point.

There are only three liquids for which Prof. Schiff notices that the value of $\mathrm{N}$, as calculated from the curve, differs markedly from the observed value. These are-

$$
\begin{aligned}
& \text { Amylene } \left.\left.\left(\mathrm{C}_{5} \mathrm{H}_{10}\right) \text {, for which } \mathrm{N} \text { (obsd. }\right)=22 \text {, and } \mathrm{N} \text { ( } \text { (calcd. }\right)=23.4 \\
& \begin{array}{rlll}
\text { Diallyl }\left(\mathrm{C}_{6} \mathrm{H}_{10}\right) & =18.4 & , & =20.5 \\
\text { Ethylene-chloride }\left(\mathrm{C}_{3} \mathrm{H}_{4} \mathrm{Cl}_{2}\right), & =24.6 & , & =20.5
\end{array}
\end{aligned}
$$

In the first case the disagreement is explained by the presence of impurity; in the second, impurity is very possibly the cause; while in the third it is possible that the equation $\mathrm{Cl}=\mathrm{H}_{7}$ is not applicable to substances in whose formula more than a single carbon atom is represented, a point which the author hopes to clear up by further investigation. We observe, however, that to these disagreements should be added the case of ethyl-isobutyrate $\left.\mathrm{C}_{6} \mathrm{H}_{12} \mathrm{O}_{2}\right)$, for which $\mathrm{N}$ as given by the curve is $13 \cdot \mathrm{I}$, while the observed value was 12.3 , a deviation of 7.5 per cent. On this the author makes no remark.

We will venture here to call attention also to a slight error that pervades all Prof. Schiff's results. We refer to the manner in which he corrects for the meniscus. The importance of this correction is in these measures very considerable, since the total elevation observed is always less than $10 \mathrm{~mm}$. and sometimes less than $5 \mathrm{~mm}$, and the correction is sometimes as much as 2 per cent. of the whole. Prof. Schiff, rejecting as insufficiently accurate Laplace's correction, which is based on the assumption that the surface of the meniscus may be regarded as that of a hemisphere of the same radius as the tube, and which consists therefore in adding to the observed height one-third of this radius, prefers to measure the height of the meniscus directly and to take as the correction one-third of the arithmetical mean between the observed height and the radius of the tube. In doing this he assumes that the surface may be regarded as that of a sphere of radius very appreciably greater than that of the tube, and gives a diagram in which it is so represented; but if this assumption or representation were correct, the laws of capillary tubes would be very different from what they are; moreover, according to theory, the form of the meniscus, and therefore the correction, must always be the same for liquids with the same capillary elevation; but Prof. Schiff's correction, based on the direct measurement of the meniscus, varies very considerably for elevations that are almost identical, which shows that the measures of the meniscus are not to be relied on: thus in the case of ethyl-toluol (para) $\left(\mathrm{C}_{9} \mathrm{H}_{2}\right)$ the elevation is $603 \mathrm{~cm}$., and the correction $013 \mathrm{~cm}$., while for isobutyl-formiate $\left(\mathrm{C}_{5} \mathrm{H}_{10} \mathrm{O}_{2}\right)$ the elevation is $599 \mathrm{~cm}$., but the correction '008 c.m. and in many cases one of two liquids which must theoretically have the greater correction has in point of fact the smaller. In order to see how far the empirical correction was at fault, we have selected one of Prof. Schiff's measures in which the elevation has about its mean value, and have calculated for comparison the correction of Hagen and Desains, which is based on the very approximately accurate assumption that the meniscus may be regarded as an oblate spheroid, and which is said to have been verified (? in the case of water) for tubes whose diameter attained as much as $4.6 \mathrm{~mm}$. The following is the result :-

$$
\begin{aligned}
& \text { Propyl Formiate: observed elevation }=\quad 6.45 \\
& \text { " " Laplace's correction } \quad=-0.1046 \\
& \begin{array}{lll}
", \quad & \text { Hagen and Desains' correction } & =-0.102 \\
, & \text { ", Schiff's correction } & =-0.07
\end{array}
\end{aligned}
$$

Corrected value (Schiff) 6.38; (Hagen and Desains), 6.348 mm.

It will thus be seen that an error of about $\frac{1}{2}$ per cent. in the value of the surface-tension has entered into the result on this occasion, and that more has been lost than gained by substituting the empirical correction for that of Laplace; in some cases the error will be rather greater.

The importance in molecular physics of the step which Prof. Schiff has taken cannot easily be overrated. If it were only that he had found that isomeric substances have the same surfacetension at the boiling-point, that alone would have been a fact of great importance in reference to the interpretation of what we are accustomed to call the internal vapour-tension in a liquid ; but in the system of absolute atomic equivalences with respect to surface-tension, and the knowledge of the manner in which the surface-tension varies with variations of the atomic equivalent, he has given to the physicist now for the first time most important data for correlating the surface-tension with the molecular actions existing expectively in the mass of the liquid and in the vapour above it.

A. M. W.

\section{RESEATCHES ON THE ORIGIN AND LIFE-} HISTORIES OF THE LEAST AND LOWEST LIVING THINGS ${ }^{1}$

TO all who have familiarised themselves, even cursorily, with modern sc entific knowledge, it is well known that the mind encounters the infinite in the contemplation of minute, as well as in the study of vast natural phenomena. The farthest limit we have reached, with the most gigantic standard of measurement we could well employ, in gauging the greatness of the universe, only leaves us with an overwhelming consciousness of the awful greatness-the abyss of the infinite-that lies beyond, and which our minds can never measure. The indefinite has a limit somewhere; but it is not the indefinite, it is the measureless, the infinite, that vast extension forces upon our minds. In like manner, the immeasurable in minuteness is an inevitable mental sequence from the facts and phenomena revealed to us by a study of the minute in nature. The practical divisibility of matter disclosed by modern physics may well arrest and astonish us. But biology, the science which investigates the phenomena of all living things, is in this matter no whit behind. The most universally diffused organism in nature, the least in size with which we are definitely acquainted, is so small that fifty millions of them could lie together in the one-hundredth of an inch square. Yet these definite living things have the power of locomotion, of ingestion, of assimilation, of excretion, and of enormous multiplication, and the material of which the inconceivably minute living speck is made, is a highly complex chemical compound. We dare not attempt a conception of the minuteness of the ultimate atoms that compose the several simple clements that thus mysteriously combine to form the complex substance and properties of this least and lowliest living thing. But if we could even measure these, as a mental necessity, we are urged indefinitely on to a minuteness without conceivable limit, in effect, a minuteness that is beyond all finite measure or conception. So that, as modern physics and optics have enabled us not to conceive merely, but to actually realise, the vastness of spatial extension, side by side

${ }^{x}$ By Rev. W. H. Dallinger, LI.D., F.R.S., F.L.S., Pres.R.M S. 